\title{
Identificación del Estrés Térmico en Vacas Lecheras ${ }^{1}$
}

\section{iLa Clave para Manejar el Estrés Térmico es Entender Cuándo el Estrés Térmico Comienza!}

\section{¿QUÉ ES EL ESTRÉS POR CALOR?}

El estrés térmico ocurre cuando el calor producido por los procesos biológicos y el calor absorbido del ambiente excede la capacidad de la vaca para perder calor.

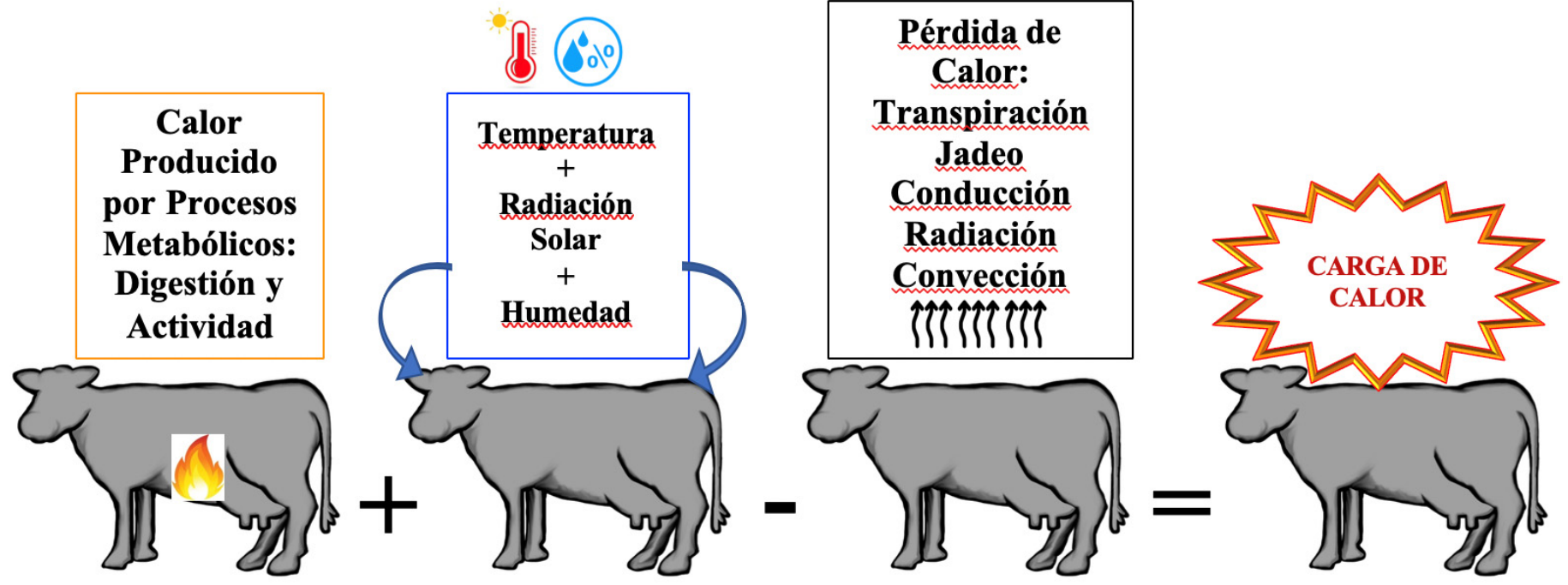

Para evaluar el estrés térmico en vacas lecheras se utiliza el Índice de Temperatura y Humedad, que se calcula en base a la temperatura ambiente y la humedad relativa.

\section{Relación entre el Índice de Temperatura y Humedad, el Nivel de Estrés Térmico, la Tasa Respiratoria y la Temperatura Rectal}

\begin{tabular}{|c|c|c|c|}
\hline $\begin{array}{c}\text { Índice de Temperatura } \\
\text { y Humedad }\end{array}$ & Nivel de Estrés Térmico & Tasa Respiratoria (Ipm) & Temperatura Rectal de la Vaca \\
\hline $68-71$ & Leve & $>60$ & $101.3^{\circ} \mathrm{F}\left(38.5^{\circ} \mathrm{C}\right)$ \\
\hline $72-79$ & Leve a Moderado & $>75$ & $102.2^{\circ} \mathrm{F}\left(39^{\circ} \mathrm{C}\right)$ \\
\hline $80-89$ & Moderado a Severo & $>85$ & $104^{\circ} \mathrm{F}\left(40^{\circ} \mathrm{C}\right)$ \\
\hline$>90$ & Severo & $>100$ & $106^{\circ} \mathrm{F}\left(41^{\circ} \mathrm{C}\right)$ \\
\hline
\end{tabular}

1. Este documento, AN356-Span (the English version of this document is AN356, Recognizing Heat Stress in Dairy Cows), es uno de una serie de publicaciones del Departamento de Animal Sciences, Servicio de Extensión Cooperativa de la Florida, Instituto de Alimentos y Ciencias Agrícolas, Universidad de la Florida (UF/IFAS Extension). Fecha de primera publicación: octubre 2019. Visite nuestro sitio web EDIS en <https://edis.ifas.ufl.edu>.

2. Izabella Toledo, regional specialized Extension dairy agent II, UF/IFAS Extension Northeast District; and Geoffrey Dahl, professor, Department of Animal Sciences; UF/IFAS Extension, Gainesville, FL 32611.

The Institute of Food and Agricultural Sciences (IFAS) is an Equal Opportunity Institution authorized to provide research, educational information and other services

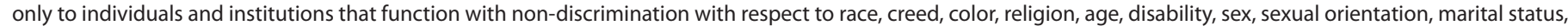

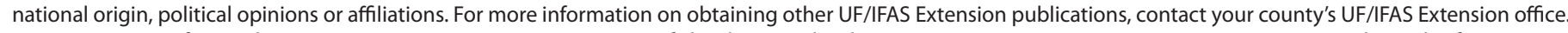
U.S. Department of Agriculture, UF/IFAS Extension Service, University of Florida, IFAS, Florida A \& M University Cooperative Extension Program, and Boards of County Commissioners Cooperating. Nick T. Place, dean for UF/IFAS Extension. 
En condiciones persistentes de CALOR, SOL y HUMEDAD, los mecanismos de termoregulación de la vaca son insuficientes para disipar todo el calor acumulado y, como consecuencia, la temperatura del cuerpo de la vaca comienza a elevarse, lo que desencadena una cascada de cambios fisiológicos para reducir esta excesiva carga de calor en el cuerpo.

\section{EFECTOS NEGATIVOS DEL ESTRÉS POR CALOR}

- Cambio de Comportamiento

- Problemas de Salud

- Reproducción y Función Immune Disminuídos

- Disminución de la Producción de Leche

- Disminución de la Rentabilidad

\section{¡Cuando los indicadores físicos de estrés térmico se manifestar, las pérdidas de producción ya han comenzado!}

\section{¿Cuáles son los Signos y Consecuencias Visibles del Estrés por Calor en las Vacas Lecheras?}

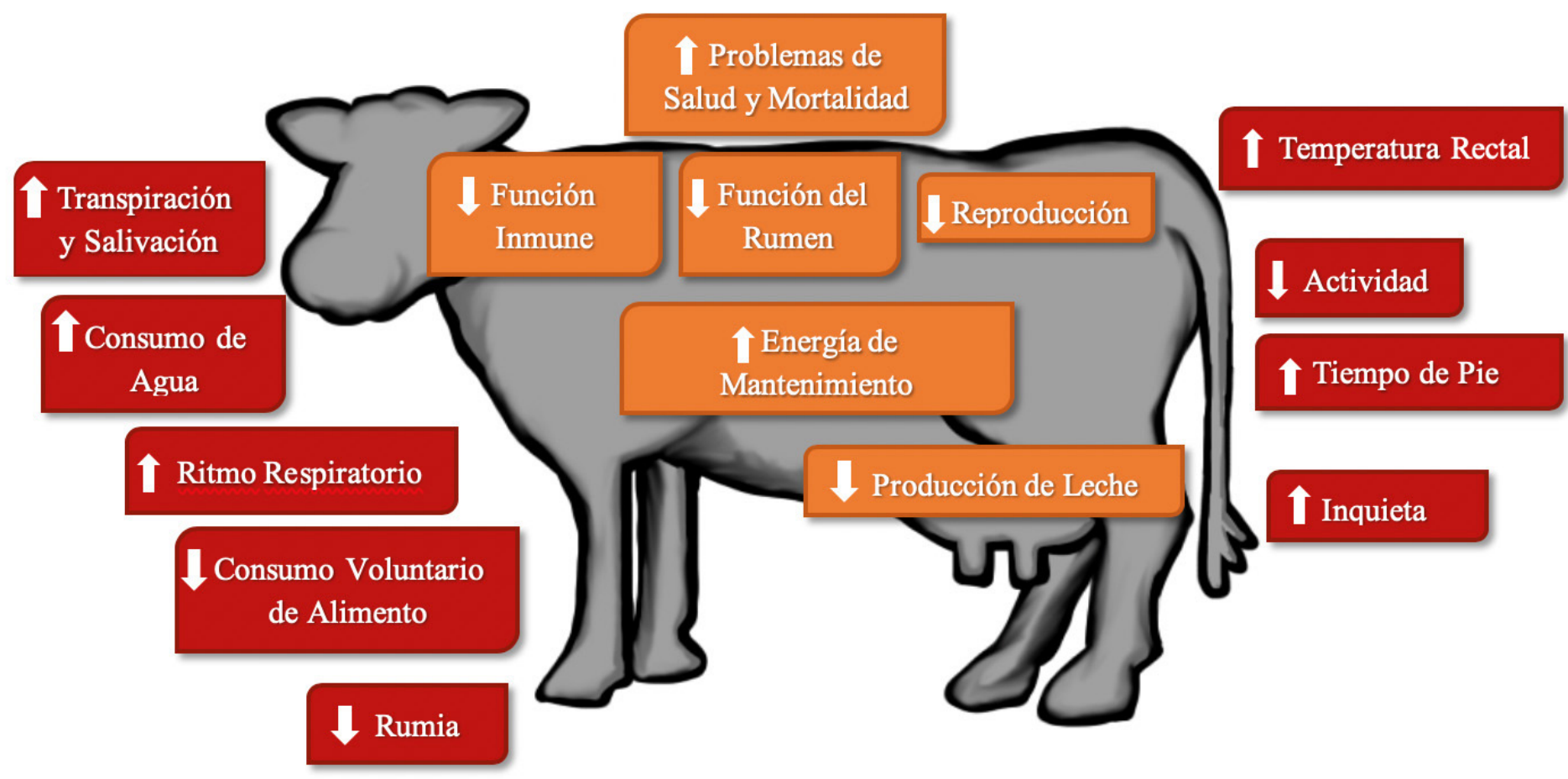

Signos Visibles del Estrés por Calor 